\title{
Lodo gerado na estação de tratamento de água Tamanduá, Foz do Iguaçu, PR, como aditivo em argilas para cerâmica vermelha. Parte II: Incorporação do lodo em mistura de argilas para produção de cerâmica vermelha
}

\section{(Sludge generated in the water treatment plant Tamanduá, Foz do Iguaçu, $P R$, as an additive in clay for red ceramic. Part II: Incorporation of sludge mixed with clay to produce red ceramic)}

\author{
R. Tartari ${ }^{1,4}$, A. N. Módenes ${ }^{1}$, S. A. Pianaro², N. Díaz-Mora ${ }^{3}$ \\ ${ }^{\prime}$ Departamento de Engenharia Química, Universidade Estadual do Oeste do Paraná - UNIOESTE, \\ Rua da Faculdade 645, Campus de Toledo, PR \\ ${ }^{2}$ Laboratório Interdisciplinar de Materiais Cerâmicos, Departamento de Engenharia de Materiais, Universidade \\ Estadual de Ponta Grossa - UEPG, Rua Carlos Cavalcanti 4748, Campus de Uvaranas, Ponta Grossa, PR \\ ${ }^{3}$ Laboratório de Materiais - LAMAT, Centro de Engenharias e Ciências Exatas, Universidade Estadual do Oeste \\ do Paraná - UNIOESTE, Rua Tarquínio Joslin Santos 1300, Campus de Foz do Iguaçu, PR \\ ${ }^{4}$ Instituto de Educação, Agricultura e Ambiente, Engenharia Ambiental, Universidade Federal do Amazonas - \\ UFAM, Rua 29 de Agosto 786, Campus Vale do Rio Madeira, Humaitá, AM \\ engrt84@yahoo.com.br
}

\begin{abstract}
Resumo
A pesquisa contempla nesta segunda etapa, misturas binárias entre as argilas da Cerâmica Santa Rita e da Cooperativa de Artesões de Foz do Iguaçu, PR, em diferentes porcentagens peso, para confecção de corpos de prova por prensagem uniaxial, sinterizados nas temperaturas de 950 e $1050^{\circ} \mathrm{C}$, e analisados pelos ensaios tecnológicos de cerâmica vermelha. Nas composições entre as argilas que apresentaram melhores desempenhos no processamento, incorporaram-se proporções de 4, 8, 12 e $16 \%$ de lodo visando agregar o resíduo a massa. Identificou-se nos resultados da produção de blocos estruturais de 6 furos pelo processo de extrusão que, $8 \%$ é o máximo de lodo a ser adicionado na massa cerâmica, onde não foi identificado trincas e deformações, com contração linear na ordem de $8,6 \%$, absorção de água de $24,6 \%$ e resistência à compressão de $42,6 \mathrm{kgf} / \mathrm{cm}^{2}$, em conformidade com as normas para produção de cerâmica vermelha para revestimento (tijolos).

Palavras-chave: cerâmica vermelha, resíduo inorgânico, lodo, estação de tratamento de água.
\end{abstract}

Abstract

The research addresses this second stage, binary mixtures of clays Ceramic Santa Rita and the Cooperative of Artisans from Foz do Iguaçu, $P R$, in different weight percentages, for making specimens by uniaxial pressing, sintered at temperatures of 950 and $1050{ }^{\circ} \mathrm{C}$, and analyzed by technological tests of red ceramic. In compositions among the clays that were better at processing, proportions of $4,8,12$ and $16 \%$ of the waste sludge were added in order to add mass. It was identified in the results of the production of building blocks 6-hole extrusion process by which $8 \%$ is the maximum of sludge to be added to the ceramic body, which was not identified cracks and deformations with linear shrinkage in the order of $8.6 \%$ water absorption of $24.6 \%$ and compressive strength of 42.6 $\mathrm{kgf} / \mathrm{cm}^{2}$ in accordance with the standards for the production of red ceramic coating (bricks).

Keywords: red ceramic, inorganic residue, sludge, water treatment station.

\section{INTRODUÇÃO}

As jazidas de argilas formadas geologicamente no município de Foz do Iguaçu, PR, segundo levantamento realizado pela Mineropar em 1990, sobre as potencialidades minerais, foi estimada a existência de três milhões de toneladas de argilas com características tecnológicas satisfatórias para produção de cerâmica vermelha [1].

A ocupação territorial do município de Foz do Iguaçu, PR, se desenvolveu principalmente a partir da construção da Hidrelétrica de Itaipu na década de 70, sem planejamento de uso e ocupação do solo, e devido à inexistência de informações geológicas dos recursos minerais existentes, encontram-se atualmente inúmeras áreas com minerais 
no subsolo ocupado por conjuntos habitacionais que impossibilita o processo de lavra. As empresas ceramistas atuantes no município utilizaram na produção de telhas e tijolos grandes quantidades das argilas consideradas de alta plasticidade, sem a incorporação de argilas de características "magras", devido à inexistência de informações tecnológicas para melhoramento das massas que, associado a processos rústicos de manufatura, corroboraram para o desperdício de produtos e também de matéria-prima, tendo um consumo médio de argilas lavradas no próprio município nos últimos 15 anos de 3.200 ton/ano, girando o total em torno de 41.657 toneladas [1]. Atualmente 6 industrias de cerâmica vermelha de pequeno porte abastecem o mercado local com média de 1,2 milhões de unidades, entre telhas e tijolos por mês [1, 3, 4]. Para Foz do Iguaçu, a estimativa de esgotamento das jazidas de argilas, recurso mineral suporte para o setor ceramista local é de até 100 anos [1], entretanto, devido à ocupação inadequada do território e, por aproximadamente $40 \%$ das jazidas de argilas do município estarem localizadas nas áreas de preservação permanente do rio Tamanduá, manancial de abastecimento de $45 \%$ da população do município [1], a lavra torna-se um grande risco para degradação e poluição do curso d água, o que já se tornou objeto de monitoramento da Empresa de Saneamento do Estado do Paraná - SANAPER [2], ocasionando pressão sob a indústria ceramista por parte dos órgãos ambientais de fiscalização. Nesta perspectiva, os insumos para operação das empresas cerâmicas locais, que fazem o abastecimento de materiais para o mercado da construção civil, tornaram-se fatores limitantes, afetando diretamente o custo destes materiais. Para continuidade das atividades, torna-se relevante a busca de outros elementos alternativos passíveis de substituição parcial das argilas "gordas" ou "magras" que na região encontram-se principalmente nas áreas de preservação permanente, caracterizados por solos hidromórficos de classificação gley. Conforme apresentado na Etapa 1, os lodos gerados na ETA Tamanduá de Foz do Iguaçu/PR, necessitam de uma destinação adequada, e de acordo com a caracterização realizada, semelhanças com as argilas indicam a possibilidade de incorporá-lo nas massas para produção de cerâmica vermelha. Portanto, esta etapa tem por objetivo estudar o método para produção da cerâmica vermelha incorporando o lodo da ETA Tamanduá às massas argilosas.

\section{MATERIAIS E MÉTODOS}

Amostras de $20 \mathrm{~kg}$ de cada matéria-prima (lodo da ETA - Tamanduá, argilas da Cooperativa de Artesões de Foz do Iguaçu - COOAFOZ (AP) e (AA), e, argilas da Cerâmica Santa Rita (OP) e (OA)) foram secas em estufa $\left(110 \pm 5^{\circ} \mathrm{C}\right)$ e submetidas à moagem em moinho martelo. Na primeira série experimental, com intuito de determinar as melhores composições por ensaios tecnológicos, prepararam-se as misturas em porcentagem peso entre as argilas (AP e AA) e (OP e OA) (Tabela I), com adição de $10 \%$ em peso de água, homogeneização manual e repouso por $24 \mathrm{~h} \mathrm{em}$ potes lacrados para manter as condições desejadas. Para cada mistura, foram confeccionados 24 corpos de prova por prensagem uniaxial, em uma prensa hidráulica Nanetti Mignon SS/EA, sob pressão de $250 \mathrm{kgf} / \mathrm{cm}^{2}$, com molde de aço prismático $(8,0 \mathrm{~cm}$ de comprimento $\mathrm{x} 3,5 \mathrm{~cm}$ de largura x $0,7 \mathrm{~cm}$ de espessura).

Tabela I - Formulações das misturas binárias das argilas em porcentagem peso.

[Table I-Components of the binary mixes of the clays in percentages by weight.]

\begin{tabular}{cccccc}
\hline $\begin{array}{c}\text { Misturas } \\
\text { "A" }\end{array}$ & $\begin{array}{c}\text { AP } \\
(\%)\end{array}$ & $\begin{array}{c}\text { AA } \\
(\%)\end{array}$ & $\begin{array}{c}\text { Misturas } \\
\text { "B" }\end{array}$ & $\begin{array}{c}\text { OP } \\
(\%)\end{array}$ & $\begin{array}{c}\text { OA } \\
(\%)\end{array}$ \\
\hline A1 & 100 & 0 & B1 & 100 & 0 \\
A2 & 70 & 30 & B2 & 70 & 30 \\
A3 & 60 & 40 & B3 & 60 & 40 \\
A4 & 50 & 50 & B4 & 50 & 50 \\
A5 & 40 & 60 & B5 & 40 & 60 \\
A6 & 30 & 70 & B6 & 30 & 70 \\
A7 & 0 & 100 & B7 & 0 & 100 \\
\hline
\end{tabular}

Na segunda série experimental, adicionou-se a fração de 4, 8,12 e $16 \%$ de lodo em peso seco nas melhores composições selecionadas pela avaliação tecnológica em cerâmica vermelha realizadas nas três fases do processamento, sendo: 8 corpos de prova após secagem em estufa após $24 \mathrm{~h}$ a $110 \pm 5{ }^{\circ} \mathrm{C} ; 8$ (oito) após sinterização a $950{ }^{\circ} \mathrm{C}$ e; 8 após sinterização a $1050{ }^{\circ} \mathrm{C}$, em forno Jung com resistências de $\mathrm{SiC}$, com programação de taxa de aquecimento de $10{ }^{\circ} \mathrm{C} / \mathrm{min}$ e patamar de $2 \mathrm{~h}$ na temperatura de sinterização. Os corpos de prova foram avaliados pelos ensaios de contração linear (\%) [5], absorção de água (\%), porosidade aparente (\%) e tensão de ruptura a flexão em três pontos $\left(\mathrm{kgf} / \mathrm{cm}^{2}\right)[6,7]$.

$\mathrm{Na}$ terceira série experimental, com resultado da porcentagem admissível de lodo detectada na formulação "B”, realizou-se um novo processamento da composição de argila por moagem, adicionando lodo nas reais condições de umidade de saída da centrífuga, seguido de homogeneização e conformação pelo método de extrusão, utilizando uma extrusora Gelenski, com molde para conformação de corpos de prova em formato de bloco estrutural de seis furos na horizontal $(32 \mathrm{~cm}$ de altura $\times 70 \mathrm{~cm}$ de comprimento $\times 36 \mathrm{~cm}$ de largura). Os corpos de prova assim confeccionados, foram sinterizados a $900{ }^{\circ} \mathrm{C}$ (temperatura usualmente utilizada em fornos industriais [9]), com taxa de aquecimento de $5^{\circ} \mathrm{C} / \mathrm{min}$ e tempo de patamar de $4 \mathrm{~h}$ na temperatura de sinterização. Os corpos de prova sinterizados, foram submetidos aos mesmos ensaios aplicados àqueles confeccionados por prensagem uniaxial, alterando-se apenas o ensaio de resistência a flexão por compressão, utilizando-se uma prensa hidráulica Shimadzu AG-I com carga máxima de $300 \mathrm{kN}$, de acordo com as recomendações da norma técnica NBR 7171 [8]. A formulação "A" com porcentagens admissíveis de lodo foi processada pelo método de moagem e incorporação do lodo 
com a umidade nas reais condições de saída da centrífuga, seguido de homogeneização e conformação pelo método de prensagem uniaxial, seguida da avaliação técnica para artesanato de cor de queima, retração linear e deformação. As amostras A e B com \% máxima de lodo foram analisadas por microscopia eletrônica de varredura e EDS.

\section{RESULTADOS E DISCUSSÃO}

A Fig. 1 mostra que os resultados das análises de contração linear das misturas foram inferiores a $5 \%$, indicando tendências de aumento com maior proporção de argilas AA e OA as massas cerâmicas e também pela influência do aumento da temperatura de sinterização. Esses fatores podem estar diretamente relacionados ao percentual de compostos químicos voláteis presentes, orgânicos e/ou inorgânicos, cuja eliminação é favorecida pelo efeito do calor, ou pela formação da fase líquida dos argilominerais que, interagindo entre si, conduzem a reorganização dos grãos densificando o corpo cerâmico [5,9], contribuindo para retração linear e perda de massa. De acordo com recomendações técnicas para cerâmica vermelha, a contração linear não deve ultrapassar $15 \%$, sendo a faixa ideal de 2 a 8\% [5]. Este indicativo é satisfatório para os resultados obtidos com as argilas utilizadas oriundas da região oeste do estado do Paraná.

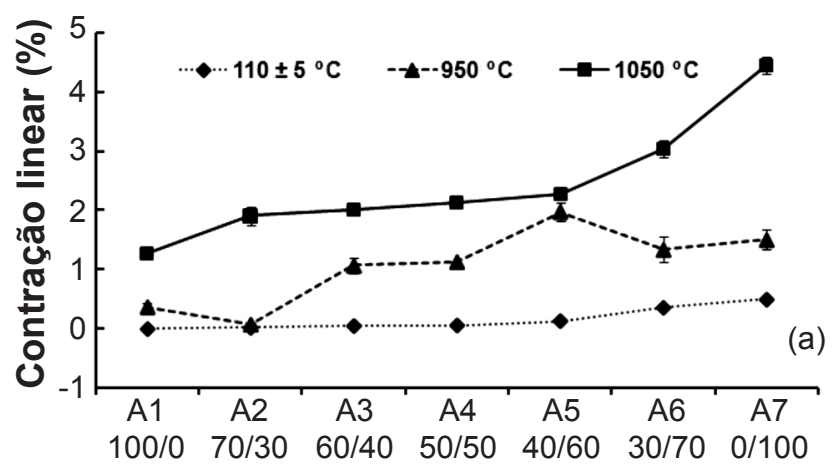

Mistura "A" (AP\%/AA\%)

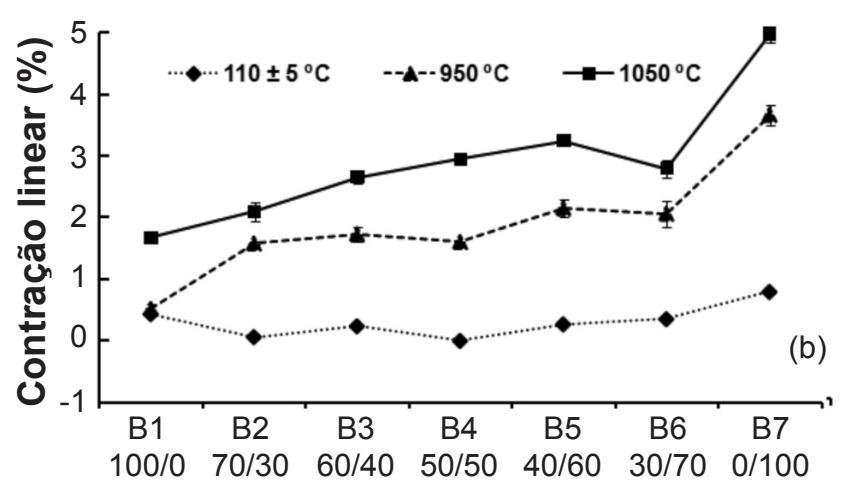

Mistura "B" (OP\%/OA\%)

Figura 1: Contração linear das misturas "a" e "b".

[Figure 1: Linear shrinkage of the mixes " $a$ " and " $b$ ".]
Após sinterização e resfriamento, o crescimento e empacotamento dos grãos como esperado, densificaram a peça cerâmica, diminuindo os espaços vazios (porosidade), inibindo a absorção de água, melhorando as propriedades de resistência mecânica. Com a adição das argilas $\mathrm{AA} \mathrm{e} \mathrm{AO} \mathrm{à} \mathrm{AP}$ e OP respectivamente, nas misturas "A" e "B", a porosidade aumentou significativamente, o que se deve às propriedades de baixa plasticidade destas argilas, bem como pela presença de quartzo que, para a formação de sua fase líquida, a temperatura necessária deva ser superior a utilizada no tratamento dos corpos cerâmicos, o que reduz ação de agrupamento e organização das partículas no arranjo da estrutura da peça cerâmica, originando falhas e pontos de descontinuidade.

Observa-se na Fig. 2 que os corpos de prova de composições, A6 (30AP+70AA), A7 (100\%AA) e B7 (100\%OA) sinterizadas na temperatura de $950{ }^{\circ} \mathrm{C}$, apresentaram resultados que não se enquadram nos requisitos normativos de absorção de água, que é de no máximo $25 \%$ [5, 7]. Já, para temperatura de $1050^{\circ} \mathrm{C}$, todas as combinações foram satisfatórias, exceto para a composição A7 (100\%AA), a qual apresentou elevada porosidade o que confirma ser desfavorável o empacotamento dos grãos das misturas com baixas porcentagens das argilas AP e OP (aumento na tendência de absorção de água).

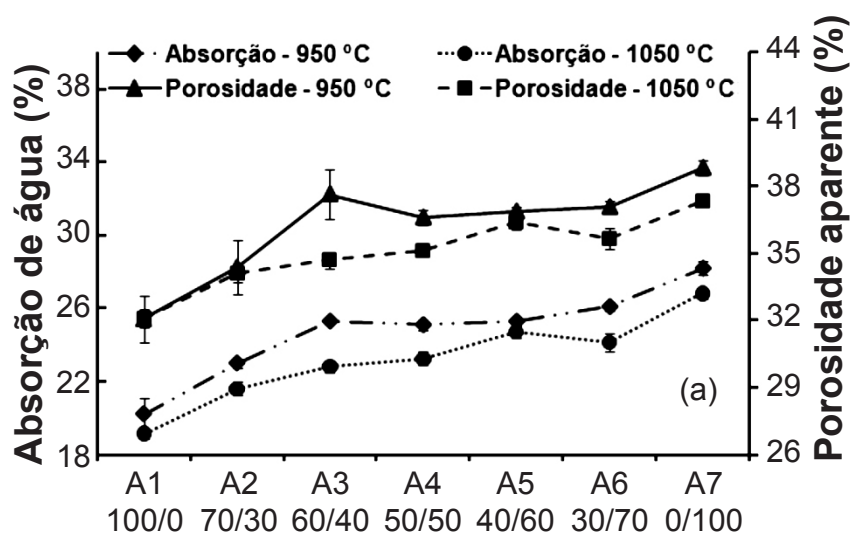

Mistura "A" (AP\%/AA\%)

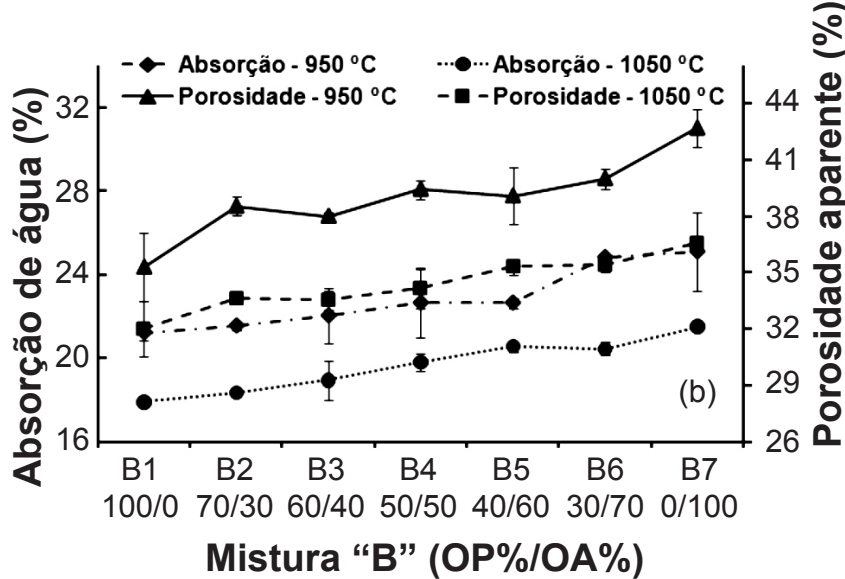

Figura 2: Absorção de água e porosidade aparente das misturas "a" e "b".

[Figure 2: Water absorption and porosity of the mixes " $a$ " $e$ " $b$ ".] 
A Fig. 3 apresenta os resultados da resistência à flexão para as misturas "A" e "B" a seco, e após sinterização nas temperaturas de 950 e $1050{ }^{\circ} \mathrm{C}$. Para corpos de prova "verdes", segundo requisitos técnicos, são desejáveis valores entre 5 a $70 \mathrm{kgf} / \mathrm{cm}^{2}$ [5]. Verificou-se que, com exceção da combinação A7 (100\%AA), todas as outras composições apresentaram resultados satisfatórios. Após a sinterização, identificou-se que houve melhorias significativas nas propriedades estruturais dos corpos de prova, entretanto, há tendências de decaimento da resistência conforme aumento da porcentagem da argila AA adicionada à mistura "A" e da argila OA adicionada na mistura "B". As composições A4 (50\%AP+50\%AA), A5 (40\%AP+60AA), $\mathrm{A} 6(30 \% \mathrm{AP}+70 \% \mathrm{AA})$ e $\mathrm{A} 7(100 \% \mathrm{AA})$ não apresentaram resultados satisfatórios após sinterização, indicando que somente a composição A2 (70\%AP+30\%AA) é suscetível de ser utilizada, bem como, a composição A1 (100\%AP), que corresponde à argila pura $\mathrm{AP}$, altamente plástica $(\mathrm{IP}=54,3)$, que juntamente com a argila pura OP (IP $=46,9)$, tornam-se referência neste trabalho, com alto índice de plasticidade.

Os resultados físico-mecânicos mostraram uma forte relação entre o índice de plasticidade e a densificação com a resistência mecânica em função do aumento da temperatura de sinterização. Na mistura "A", identificou-se que as composições A1 (100\%AP) e A2 (70\%AP+30\%AA) apresentaram melhores propriedades em relação às outras
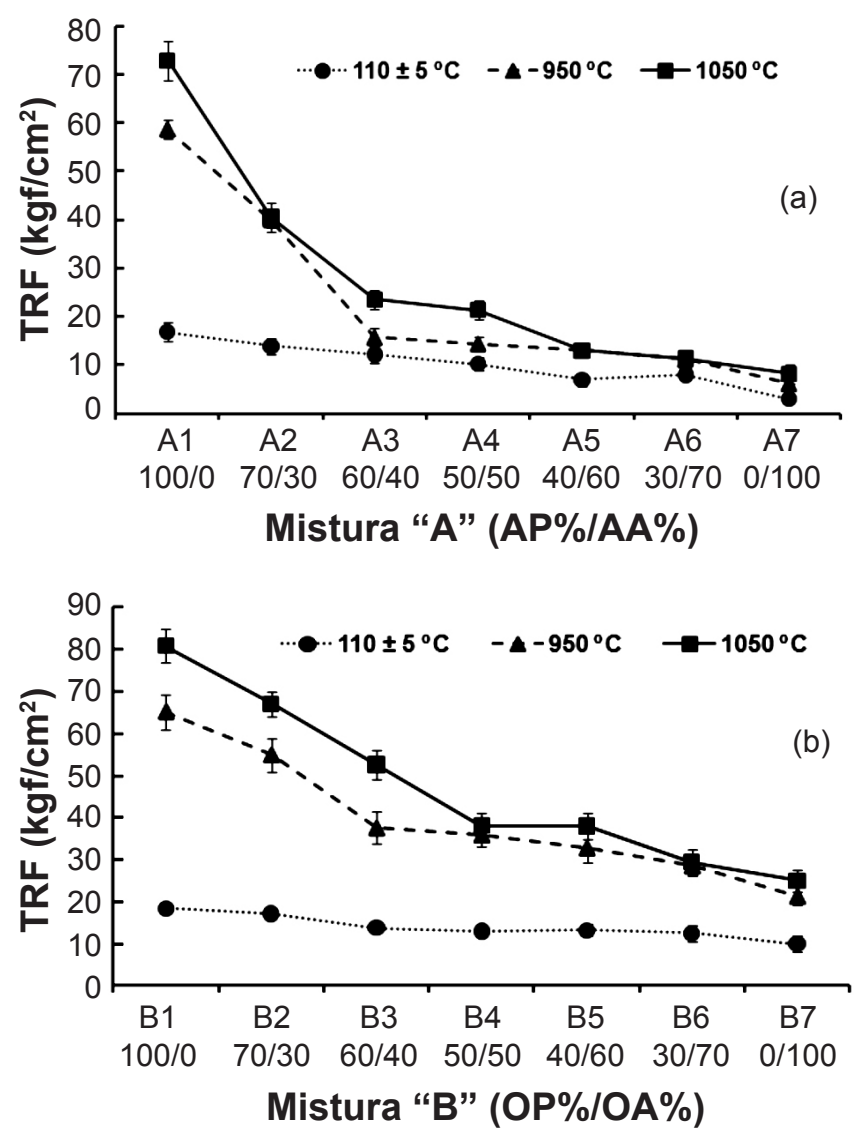

Figura 3: Resistência a flexão das misturas "A" e "B".

[Figure 3: Flexure rupture of mixes " $A$ " and " $B$ ".] cinco composições. Já, na mistura "B", as composições B1 $(100 \% \mathrm{OP})$ e $\mathrm{B} 2(70 \% \mathrm{OP}+30 \% \mathrm{OA})$ apresentaram características mais satisfatórias. Com base nesta avaliação, as composições, A1 (100\%AP), A2 (70\%AP+30\%AA), B1 $(100 \% \mathrm{OP})$ e $\mathrm{B} 2(70 \% \mathrm{OP}+30 \% \mathrm{OA})$ foram selecionadas para incorporação do lodo da ETA Tamanduá em porcentagens em peso pré-determinadas, a fim de estabelecer o máximo possível de lodo a ser adicionado às massas de argilas, sem causar deformações ou trincas às peças cerâmicas. Tais composições receberam 4, 8, 12 e $16 \%$ de lodo seco processado.

Pela análise da Fig. 4 houve aumento nas contrações lineares com a elevação da temperatura, para os corpos de prova denominados $\mathrm{A} 2(70 \% \mathrm{AP}+30 \% \mathrm{AA})$ e $\mathrm{B} 2(70 \% \mathrm{OP}+30 \% \mathrm{OA})$ com porcentagens de lodo seco e sinterizados em $1050{ }^{\circ} \mathrm{C}$. Entretanto, todas as composições em ambas as temperaturas de sinterização apresentaram resultados que se enquadram dentro dos padrões técnicos, de no máximo $15 \%$ de retração [5].

$\mathrm{Na}$ Fig. 5 as composições A1 (100\%AP) e A2 $(70 \% \mathrm{AP}+30 \% \mathrm{AA})$, ambas sinterizadas em $950{ }^{\circ} \mathrm{C}$, ao ser adicionado 12 e $16 \%$ de lodo respectivamente, apresentaram resultados de absorção de água superiores ao recomendado, que é de $25 \%$ [7], bem como trincas e deformações que
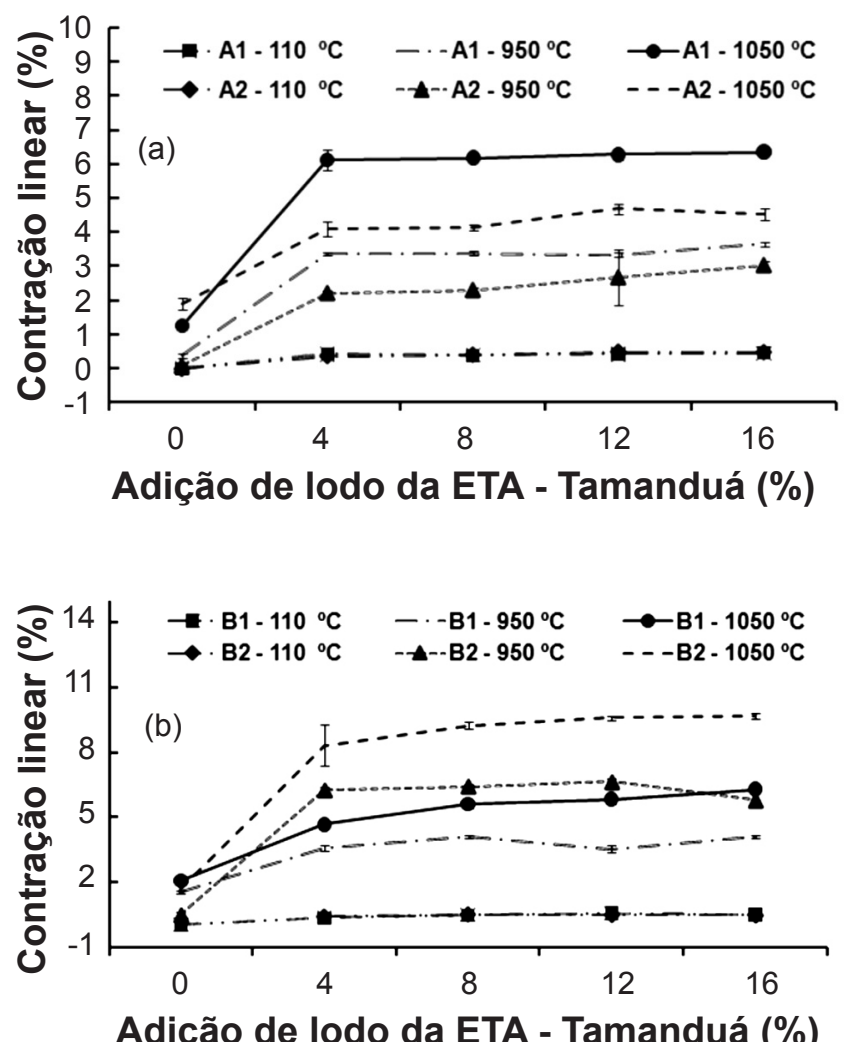

Figura 4: Contração linear total das misturas A1 (100\%AP), A2 $(70 \% \mathrm{AP}+30 \% \mathrm{AA}), \mathrm{B} 1(100 \% \mathrm{OP})$ e $\mathrm{B} 2(70 \% \mathrm{OP}+30 \% \mathrm{OA})$ com $\%$ peso de lodo.

[Figure 4: Linear shrinkage of the mixes A1 (100\%AP), A2 $(70 \% A P+30 \% A A), B 1(100 \% O P)$ and $B 2(70 \% O P+30 \% O A)$ with the \% of the sludge by weight.] 


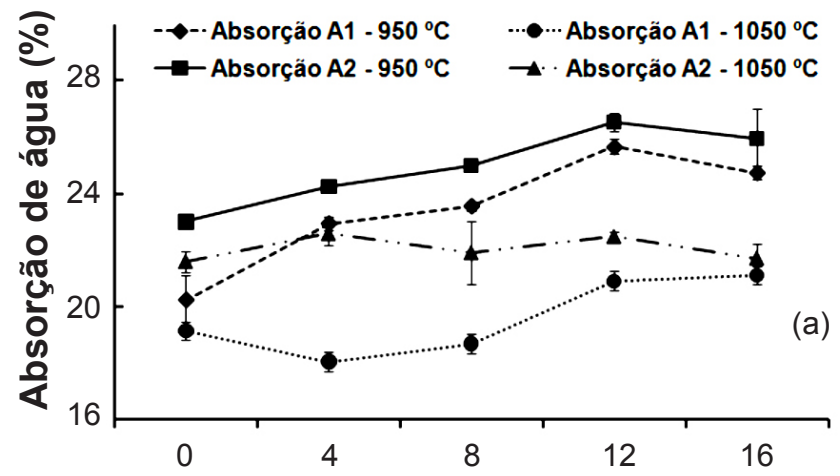

Adição de lodo da ETA - Tamanduá (\%)

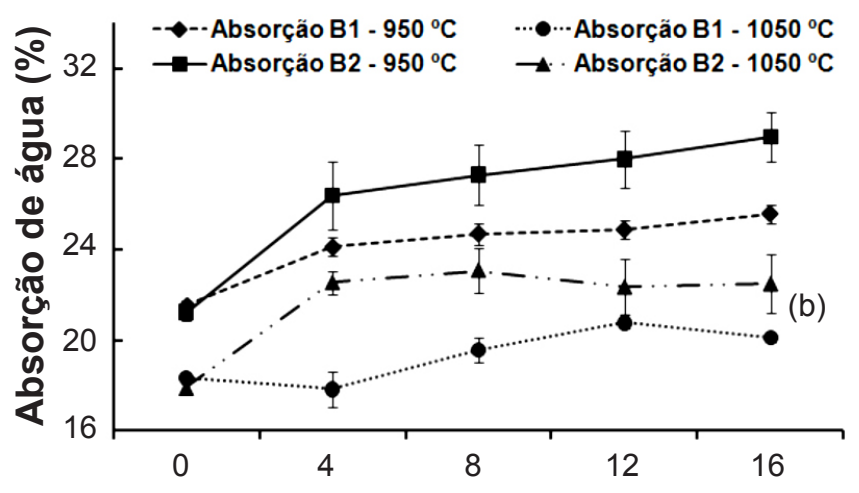

Adição de lodo da ETA - Tamanduá (\%)

Figura 5: Absorção de água das misturas A1 (100\%AP), A2 $(70 \% \mathrm{AP}+30 \% \mathrm{AA}), \mathrm{B} 1(100 \% \mathrm{OP})$ e $\mathrm{B} 2(70 \% \mathrm{OP}+30 \% \mathrm{OA})$ com $\%$ peso de lodo.

[Figure 5: Water absorption of the mixes A1 (100\%AP), A2 $(70 \% A P+30 \% A A), B 1(100 \% O P)$ and $B 2(70 \% O P+30 \% O A)$ with the $\%$ by weight of the sludge.]

são indesejáveis em peças cerâmicas. Com relação às composições com $16 \%$ de lodo sinterizadas na temperatura de $1050{ }^{\circ} \mathrm{C}$, obteve-se elevadas porcentagens de absorção de água. Observou-se também que, somente a composição B2 $(70 \% \mathrm{OP}+30 \% \mathrm{OA})$, sinterizada na temperatura de $950{ }^{\circ} \mathrm{C}$, apresentou resultados de absorção superiores as especificações técnicas e, mesmo ao ser adicionado o lodo a esta massa cerâmica, verificou-se que não houve um acréscimo significativo deste parâmetro. A adição de lodo conduziu ao aumento da porosidade da peça em $950{ }^{\circ} \mathrm{C}$ (Fig. 6), entretanto, na temperatura de $1050{ }^{\circ} \mathrm{C}$ observouse a diminuição da porosidade com a maior densificação do material em função da organização das partículas no corpo cerâmico.

A Fig. 7 mostra que ao adicionar porcentagens de lodo às composições, reduz-se significativamente a resistência mecânica, sendo que, com a adição de $12 \%$ de lodo, todas as combinações apresentaram trincas e deformações lineares, fator este que inviabiliza tecnicamente a produção de materiais cerâmicos. A composição B1 (100\%OP) com $\%$ de lodo, foi a que apresentou maior resistência à flexão, porém decaindo com o aumento da adição de lodo devida

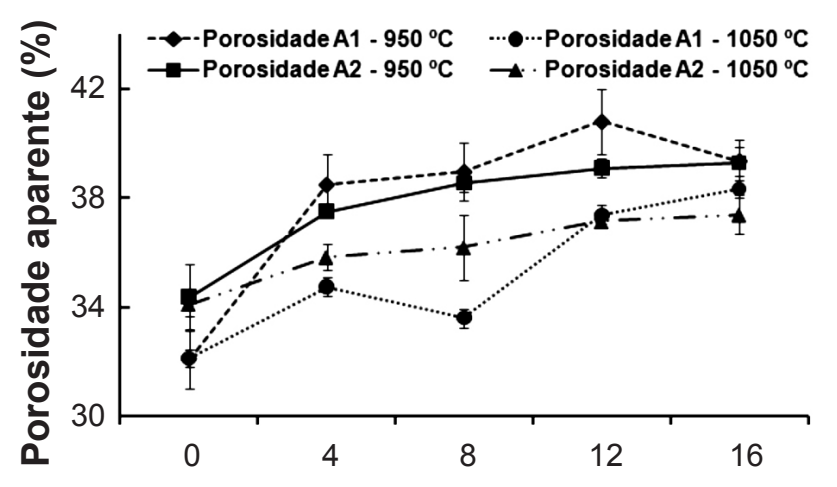

Adição de lodo da ETA - Tamanduá (\%)

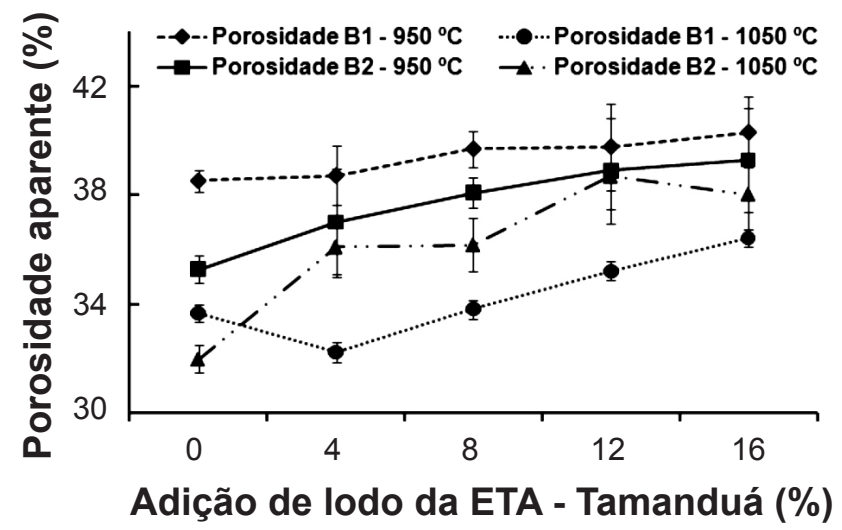

Figura 6: Porosidade aparente das misturas A1 (100\%AP), A2 $(70 \% \mathrm{AP}+30 \% \mathrm{AA}), \mathrm{B} 1(100 \% \mathrm{OP})$ e $\mathrm{B} 2(70 \% \mathrm{OP}+30 \% \mathrm{OA})$ com $\%$ peso de lodo.

[Figure 6: Porosity apparent of the mixes A1 (100\%AP), A2 $(70 \% A P+30 \% A A), B 1(100 \% O P)$ and $B 2(70 \% O P+30 \% O A)$ with the \% by weight of the sludge.]

suas características de baixa plasticidade. Com base nesses resultados, verificou-se que a porcentagem máxima desse lodo a ser incorporada à massa cerâmica, sem causar trincas e deformações, é de 8\%. Observou-se também que o lodo pode substituir parcialmente as argilas AA e OA nas misturas, uma vez que apresentaram características semelhantes.

Visando a utilização do resíduo no setor de artesanato, preparou-se a mistura (66\% AP $+26 \%$ AA $+8 \%$ lodo) conforme a metodologia descrita, sendo confeccionados artefatos cerâmicos por artesãos que, com suas experiências, relataram que: i) a forma da peça não se alterou após sinterização, o que indica baixa retração; ii) a peça cerâmica não apresentou fissuras e nem pontos de descontinuidades; iii) a cor ficou muito escura, característica não muito desejada para materiais de cerâmica artística. No geral, verificou-se que é possível a incorporação de lodo em argilas para fabricação de cerâmica artística, porém, com restrições no parâmetro cor, que não é favorável para este ramo de trabalho.

Para fabricação de tijolos estruturais de seis furos por extrusão, avaliou-se o real efeito da adição do lodo bruto na massa B2 $(66 \% \mathrm{OP}+26 \% \mathrm{AO}+8 \%$ lodo $)$ nas condições 


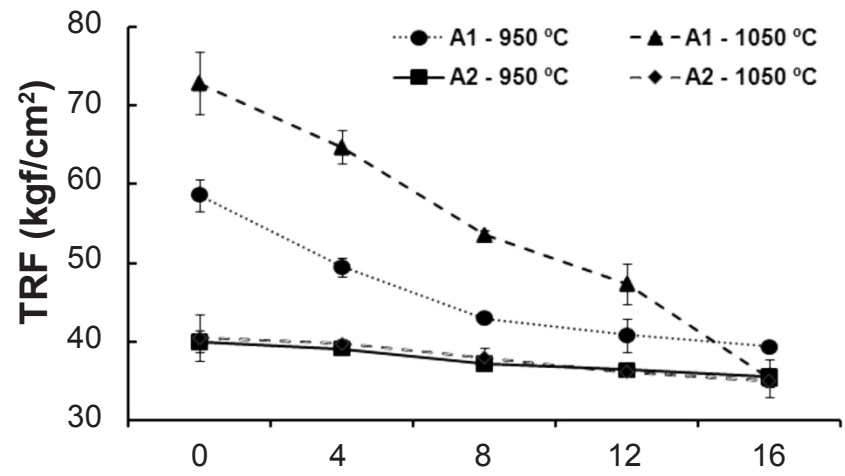

Adição de lodo da ETA - Tamanduá (\%)

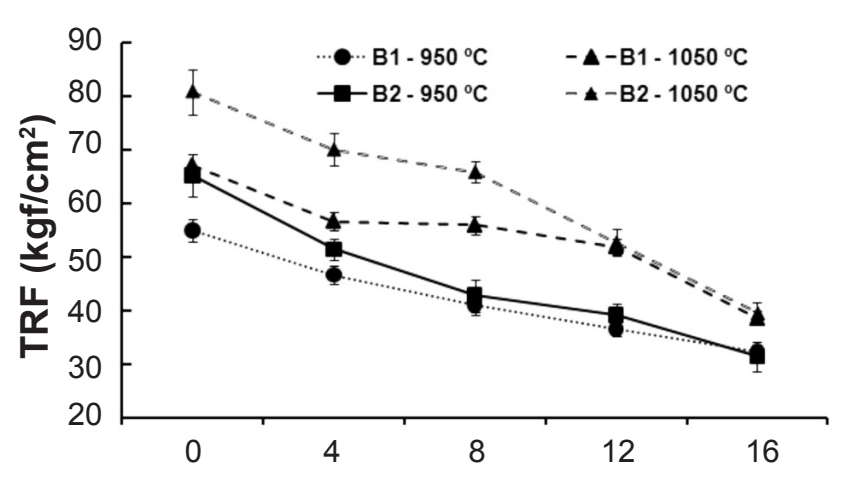

Adição de lodo da ETA - Tamanduá (\%)

Figura 7: Tensão de ruptura a flexão das misturas A1 (100\%AP), A2 (70\%AP+30\%AA), B1 (100\%OP) e B2 (70\%OP+30\%OA) com \% peso de lodo.

[Figure 7: Flexure rupture strength of the mixes $A 1(100 \% A P)$, A2 (70\%AP+30\%AA), B1 (100\%OP) and B2 (70\%OP+30\%OA).]

Tabela II - Resultados da avaliação físico-mecânica dos tijolos de seis furos.

[Table II - Evaluation results of physical-mechanical bricks six holes.]

\begin{tabular}{ccccccccc}
\hline Misturas & $\begin{array}{c}\text { CLS } \\
(\%)\end{array}$ & $\begin{array}{c}\text { CLT } \\
(\%)\end{array}$ & $\begin{array}{c}\text { AA } \\
(\%)\end{array}$ & $\begin{array}{c}\text { PA } \\
(\%)\end{array}$ & $\begin{array}{c}\text { PF } \\
(\%)\end{array}$ & $\begin{array}{c}\text { MEA } \\
\left(\mathrm{g} / \mathrm{cm}^{2}\right)\end{array}$ & $\begin{array}{c}\text { TRC } \\
\left(\mathrm{kgf} / \mathrm{cm}^{2}\right)\end{array}$ & $\begin{array}{c}\text { TRCs } \\
\left(\mathrm{kgf} / \mathrm{cm}^{2}\right)\end{array}$ \\
\hline Com lodo & $6,2 \pm 0,8$ & $8,9 \pm 0,3$ & $24,6 \pm 0,2$ & $38,3 \pm 2,3$ & $11,1 \pm 0,0$ & $1,71 \pm 0,1$ & $42,6 \pm 1,2$ & $5,3 \pm 0,8$ \\
Sem lodo & $1,2 \pm 0,3$ & $2,5 \pm 0,6$ & $21,4 \pm 0,4$ & $34,0 \pm 0,8$ & $9,4 \pm 0,1$ & $1,7 \pm 0,1$ & $66,1 \pm 0,1$ & $7,4 \pm 1,2$ \\
\hline
\end{tabular}

CLS: contração linear de secagem; CLT: Contração linear total; AA: absorção de água; PA: Porosidade aparente; PF: Perda ao fogo; MEA: Massa específica aparente; TRC: tensão de ruptura a compressão; TRCs: tensão de ruptura a compressão a seco.

(a)

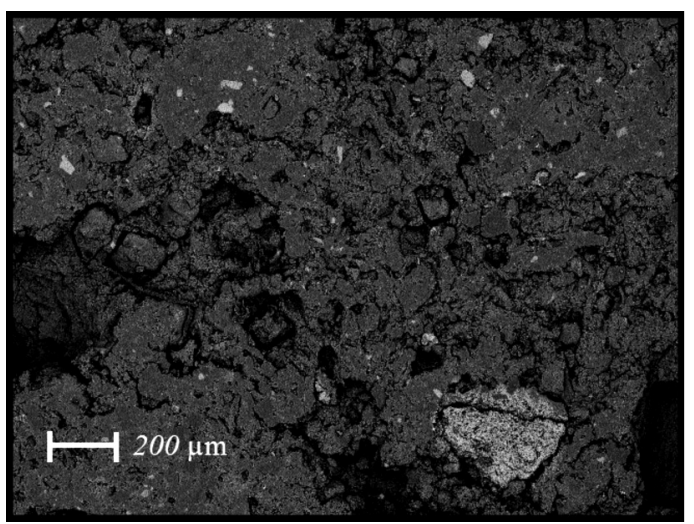

(b)

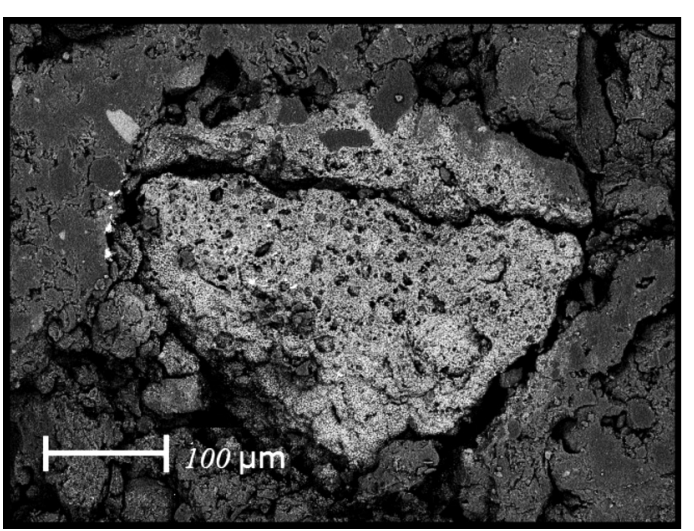

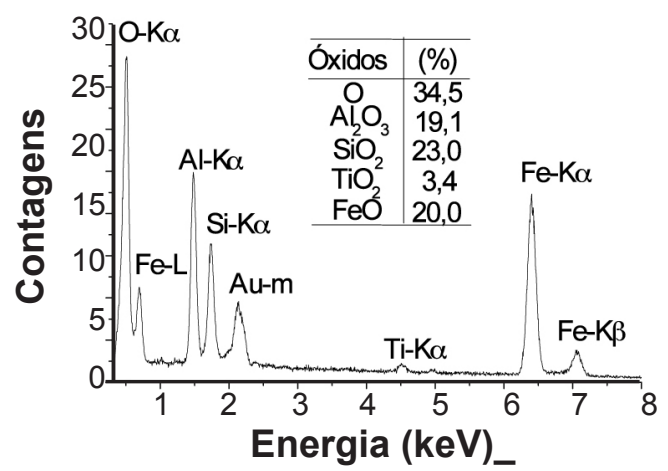

(d)

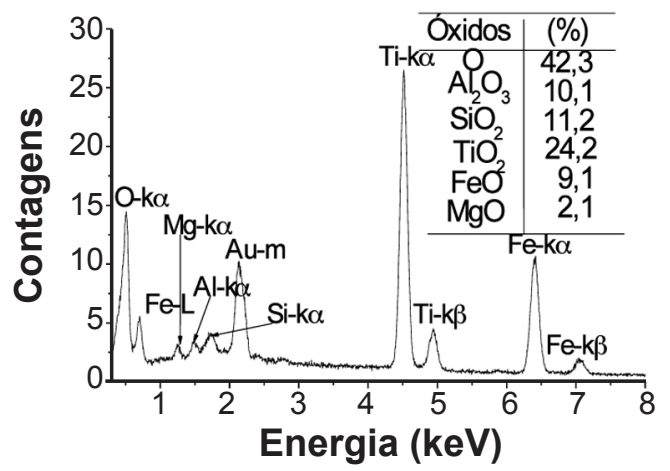

(C)

Figura 8: Microanálise obtida por EDS da amostra A2 (66\%AP+26\%AA+8\%lodo) sinterizada em $950{ }^{\circ} \mathrm{C}$, destacando o detalhe do titânio em cinza claro.

[Figure 8: Micrographs obtained by SEM of the sample A2 (66\%AP+26\%AA+8\%sludge) sintered at $950{ }^{\circ} \mathrm{C}$ highlighting the titanium gray.] 
(a)

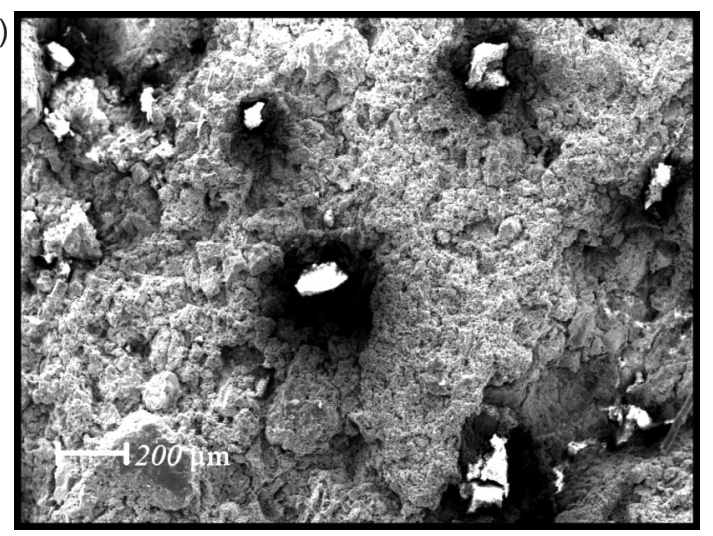

(b)

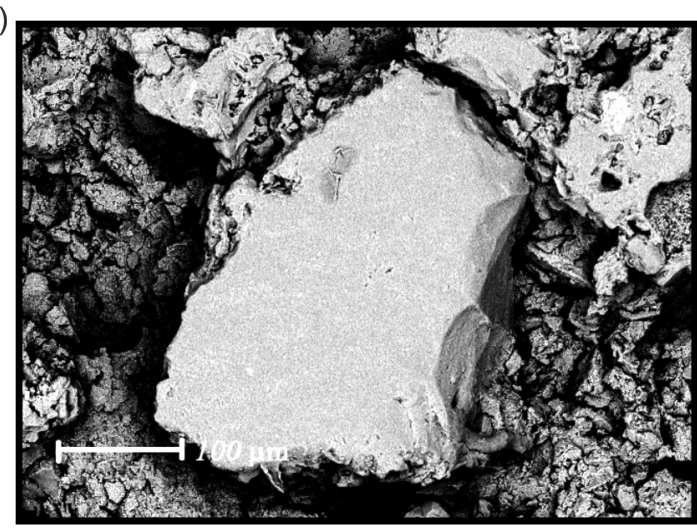

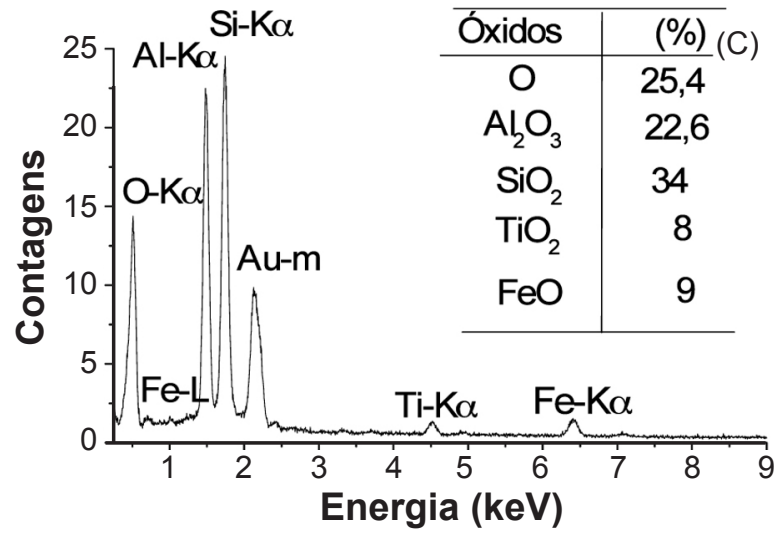

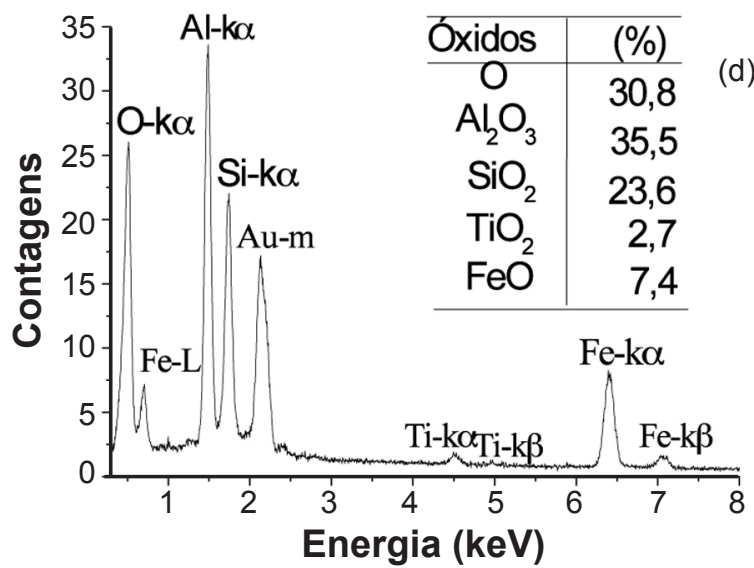

Figura 9: Microanálise obtida por EDS da amostra B2 (66\%OP+26\%AO+8\%lodo) sinterizada em $950{ }^{\circ} \mathrm{C}$, destacando o detalhe do alumínio. [Figure 9: Micrographs obtained by SEM of the sample B2 $\left(66 \% \mathrm{OP}+26 \% \mathrm{AO} 8 \%\right.$ sludge) sintered at $950{ }^{\circ} \mathrm{C}$ highlighting the detail of aluminum.]

pré-determinadas, comparando a influência na mesma composição B2 $(70 \% \mathrm{OP}+30 \% \mathrm{AO})$ sem lodo. Salienta-se que no processamento de mistura entre as argilas, o lodo foi incorporado nas condições de umidade reais de saída da centrífuga da ETA Tamanduá, de forma que seus 76,4\% de umidade contida favoreceram a atividade de interação entre os argilominerais, reduzindo com isto a quantidade de água adicionada para obtenção de uma massa plástica com ótimas condições de trabalhabilidade.

Pelos resultados apresentados na Tabela II, a contração total da composição com lodo foi mais elevada que a sem lodo, devido à perda ao fogo $(20,4 \%)$ de matéria de origem orgânica e inorgânica presente no resíduo, e também pela redução do grau de compactação entre os grãos, o que favoreceu o aumento de canais internos entre as partículas, fazendo com que a água presente fosse eliminada no processo de secagem [11]. Em relação a absorção de água, verificou-se que os resultados encontraram-se dentro dos parâmetros estabelecidos pela norma [7], entretanto, nota-se que a porosidade aumentou com a adição de lodo à massa, que possui ação de desplastificante. A tensão de ruptura diminuiu com a adição de $8 \%$ de lodo, entretanto, encontra-se dentro dos padrões exigidos para blocos cerâmicos estruturais de seis furos (tijolo) [8].

Ambas as composições com $8 \%$ de lodo apresentaram resultados satisfatórios perante fabricação de blocos estruturais e artefatos artesanais, os quais foram caracterizados por microscopia eletrônica de varredura (MEV) e microanálise (EDS). Nas micrografias (a) e (c) da Fig. 8, observam-se descontinuidades e cavidades na microestrutura da amostra $\mathrm{A} 2$ (66\% $\mathrm{AP}+26 \% \mathrm{AA}+8 \%$ lodo), onde se identificou a presença de óxido de titânio na superfície da amostra e observaram-se grãos com diferentes granulometrias e que não sofreram coalescência, com formato irregular e trincas ao longo de toda sua superfície, indicando baixa interação com os outros argilominerais presentes. Fatores estes que evidenciam as possíveis causas do aumento da porosidade e redução da resistência mecânica da peça cerâmica. Destaca-se na região em cor cinza clara nas micrografias a composição majoritária dos óxidos de titânio, silício, alumínio e ferro, conforme o espectro de raios $\mathrm{X}$ apresentados na Fig. 8d distinta da matriz Fig. 8b.

Na micrografia da Fig. 9, referente a composição B2 $(66 \% \mathrm{OP}+26 \% \mathrm{AO}+8 \%$ lodo $)$ sinterizada a $950{ }^{\circ} \mathrm{C}$, verificase grande percentual de alumino-silicato que forma a estrutura da cerâmica. Observa-se que a granulometria é mais homogênea com relação à Fig. 8, com maior adesão entre os grânulos. Destaca-se na superfície da amostra a presença do óxido de alumínio, com grânulos 
dos minerais que se solidificaram isoladamente com distintas formas. Na micrografia (a), identificou-se bom empacotamento das partículas, com muitos grãos de mesma aparência granulométrica, seguros pela solidificação de argilominerais distintos, que contribui favoravelmente para redução da absorção de água. Na micrografia (b), observase que a estrutura do material é homogenea com presença majoritária de óxidos de alumínio e de silício conforme espectro de EDS.

\section{CONCLUSÕES}

O melhor empacotamento dos grãos ocorreu com a adição de $70 \%$ das argilas $\mathrm{APe}$ OP nas misturas, contribuindo diretamente para os resultados de menor absorção de água e maior resistência mecânica, devido à característica de plasticidade dessas argilas que diretamente influenciaram na melhoria da formulação da massa cerâmica. Em todos os casos, as retrações lineares não ultrapassaram os requisitos normativos de $15 \%$, entretanto, a perda ao fogo elevada do lodo contribuiu para o aumento da contração linear da peça cerâmica. Adições de lodo superiores a $8 \%$ nas composições alteram negativamente as propriedades físico-mecânicas favorecendo o surgimento de trincas e deformações nas peças cerâmicas. A produção de tijolos pelo processo de extrusão apresentou viabilidade em receber porcentagens admissíveis de lodo à massa com umidade real de saída da centrífuga na preparação da massa para fabricação de cerâmica vermelha. Os resultados mostraram que o lodo gerado na Estação de Tratamento de Água da unidade Tamanduá em Foz do Iguaçu, PR, não pode ser usado como componente majoritário em massas cerâmicas. No entanto, este resíduo pode ser usado em pequenas quantidades em massas argilosas (até o limite de 8\%), nas condições de umidade reais de saída da centrífuga, vista a redução da exploração da matéria-prima argila e contribuindo também para a economia na adição de água no processo de produção de cerâmica vermelha por extrusão.

\section{AGRADECIMENTOS}

Os autores agradecem a SANEPAR/SANETEC pelo financiamento e incentivo a pesquisa, ao FPDTA/PTI, à Fundação Araucaria e ao CNPq pelas bolsas de estudo de mestrado e iniciação científica.

\section{REFERÊNCIAS}

[1] Mineropar, Minerais do Paraná S/A., Programa de Levantamento das potencialidades minerais dos municipios: Foz do Iguaçu-PR, Curitiba, Foz do Iguaçu, PR (1990) 83 p. [2] SANEPAR, Plano de Gestão e Manejo do Manancial do Rio Tamanduá, Foz do Iguaçu - PR, SANEPAR 10 (2002).

[3] Mineropar, Produção mineral por município (1995-2004), Disponível em <http://www.mineropar.pr.gov.br>. Acesso realizado em novembro de 2009.

[4] IPARDES, Caderno Estatístico Município de Foz do Iguaçu, PR (03/2009).

[5] P. S. Santos, Ciência e Tecnologia de Argilas, $2^{\mathrm{a}}$ Ed., v.1 Edgar Blucher, S. Paulo, SP (1989).

[6] ABNT, Associação Brasileira de Normas Técnicas - NBR 6113, Material refratário denso conformado - determinação da resistência à flexão à temperatura ambiente, Rio de Janeiro, RJ (1990).

[7] ABNT, Associação Brasileira de Normas Técnicas - NBR 6220, Material refratário denso - determinação da massa especifica aparente, porosidade aparente, absorção e massa especifica aparente da parte sólida, Rio de Janeiro, RJ (1989). [8] ABNT, Associação Brasileira de Normas Técnicas - NBR 7171, Bloco cerâmico para alvenaria, especificações, Rio de Janeiro, RJ (1992).

[9] W. D. Kingery, H. K. Bower, D. R. Uhlmann, Introduction to ceramics, $2^{\text {nd }}$ Ed., John Wiley \& Sons, New York, EUA (1975).

(Rec. 25/04/2010, Rev. 06/07/2010, Ac. 20/08/2010) 